\title{
FOSTERING LMD ENGLISH LANGUAGE LEARNERS' SKILLS AND COMPETENCIES AS A WAY TO FACE NEW CHALLENGES IN EDUCATION
}

\author{
MOHAMED KIES 1 \\ Djilali Liabes University, Sidi Bel Abbes (Algeria)
}

\section{RESUMEN}

Asistimos hoy día a un un debate creciente sobre la necesidad e importancia de incorporar lo que frecuentemente denominamos Habilidades y Competencias del Siglo Veintiuno, que son aptitudes y habilidades cuyo desarrollo se requiere en diferentes situaciones de aprendizaje. Desde luego, son requisitos necesarios para la empleabilidad y se contemplan como componentes esenciales que completan y refuerzan habilidades académicas básicas y tradicionales. Por ejemplo, la planificación y el establecimiento de objetivos la colaboración y la comunicación, la persistencia, la flexibilidad y la toma de iniciativas contribuirían al éxito académico del alumnado, en sus orientaciones profesionales e, incluso, socialmente. Fomentar las habilidades y las competencias, sin duda, contribuiría a hacer que nuestro alumnado manejase el conocimiento de una manera más efectiva, reflexiva y productiva.

Palabras clave: Competencias del siglo XXI para el aprendizaje de idiomas, sistemas argelinos LMD (License Master Doctorate)

\begin{abstract}
There is a growing debate at present time on the necessity and importance of incorporating what is often referred to as Twenty First Century Skills and Competencies that are attitudes and abilities required to be developed in different learning situations. Indeed, they are necessary requirements for future employability and are seen as essential components completing and reinforcing traditional basic academic skills. For example, planning and objectives-setting, collaborating and communicating, persistence, flexibility and initiative-taking, would help to make students successful academically, in their future professional orientations, and even socially. Fostering skills and competencies would undoubtedly contribute to making our students handle and deal with knowledge in a more effective, reflective and productive manner.
\end{abstract}

Key words: Language learning-21st century skills-Competencies, Algerian LMD System (License Master Doctorate)

\section{Introduction}

Moreover, the attempt to develop some Key Competencies along with what is often referred to as $21 \mathrm{st}$ Century Skills, has become, today, a necessary pedagogical priority to be tackled in the License Master Doctorate (LMD) system. Recently, in fact, educational policy makers in some developed countries have started to focus on the concept of Key Competencies- attitudes and abilities that the learner should acquire in order to cope with new situations-. Thus, Twenty First Century Skills can be a prerequisite requirement for university students to be equipped with, to have better chances of employability in an increasingly interconnected world. It appears, then, necessary to evaluate the possibility to integrate these skills and competencies among the LMD pedagogical priorities and propose a series of actions that could

\footnotetext{
1E-mail: kiesmed@yahoo.fr
} 
foster our learners' independent learning: a concept which is at the heart of the LMD reform. In the present paper, we will tackle some of the LMD pedagogical priorities in the Algerian university context, as far as language learning is concerned, precise what is meant by competencies and 21 st century skills, and then describe some pedagogical implications of their integration in the organization of higher studies in Algeria.

\section{The LMD system in Algeria}

The LMD system is inspired from the Anglo-Saxon structure of higher studies, namely Bachelor, Master, Doctorate. It is an attempt to harmonize the different university systems in the world. It was adapted in different regions such as North America, Asian countries and by the majority of European states. In Europe, this project was the direct consequence of the Bologna Process initiated in 1998.

Algeria decided to adopt the principles of the Bologna Process during the academic year 2004/2005 in order to apply this new organization of studies, within the framework of a general and an ambitious reform supposed to bring fresh air to universities. The objective of official authorities was to adapt the Algerian system to the international one, and progressively introduce new pedagogical offers supposed to supplement the traditional pedagogical practices. The LMD system assumes to guarantee a wide range of pedagogical objectives essentially centered on the students, who are meant to be the main target of such a reform. Though many problems and constraints remain unsolved, its generalization in all the Algerian universities requires, now more than ever, a re-thinking about objectives, contents, skills and competencies needed to undertake such a challenging task.

The following is a non exhaustive list of learning goals that should be fulfilled during the teaching/ learning process in the Algerian LMD context:

- To involve the learner in the conception of pedagogical content by taking into account his profile and his needs in order to get a better accomplishment of the teacher's mission, in addition to encouraging an instructive debate between the instructor and his learners

- To prepare and equip students for their future professional life

- To guarantee diversity in the learning choices that can reflect a more consistent pedagogical offer

- To detect the learner's difficulties in order to find efficient teaching solutions

- To adopt a different assessment approach

- To encourage continuous research and foster personal and collective initiatives

- To promote the development of transversal competencies such as the mastery of foreign languages and computing sciences

- To develop the learner's autonomy, by helping him discover and acquire a wider range of competencies that are essential in different situations and contexts

This last objective could directly lead us to the narrow relationship that could exist between the LMD students' needs and the Key Competencies that seem to be important tools for personal learning and achievement, along with the Twenty First Century Skills, which are necessary for their future employability.

\section{Key Competencies and Twenty first Century Skills}

The term competency refers to the ability of doing something efficiently. According to Rychen and Tiana (2004), the concept of competency is defined as the ability to successfully meet complex demands or to carry out a particular activity or task. They put forward an understanding of key competencies as "(...) internal mental structures of abilities, capacities and dispositions embedded in the individual."(p.21).

Similarly, Key Competencies are defined by the Council of Europe (2006) as a combination of knowledge, skills and attitudes appropriate to a particular context. Thus, the mastery of such skills can guarantee an improved performance, a readiness to take advantage from new opportunities and the ability 
to link specific skills to particular needs and demands. In brief, they facilitate the personal development, employment and social integration, and the contribution to a better local environment.

If we want to use some of the Council of Europe framework of key competencies, for instance, we can retain the following ones: Communicating in foreign languages, Learning to learn, Interpersonal, Intercultural and Social competencies, Entrepreneurship, Basic competence in Technology, etc.

Therefore, key competencies are the necessary and appropriate knowledge, skills and attitudes that learners need to develop for their own personal fulfillment but also, for their future needs. Out of these competencies, other skills and aptitudes derive and need to be developed by our learners too, such as: Critical thinking, Creativity, Initiative taking, Problem-solving, Risk assessment, Decision taking, etc.

By the same token, Crisan (2006:125) mentions the work of Bransford (2000); Singer (2002); Singer (2006)\& Spelke (2002) when assuming that "(...)in line with the research in Cognitive Psychology... competencies are the best means to transfer knowledge and skills in new and dynamic situations/contexts." He further emphasizes the fact that the more we are able to understand the nature of competence, the more it will be easier for us to study the learning process and design the best conditions for achieving and assessing acquired competence. (Crisan, 2006:125), mentioning Glaser (1988:35).

On the other hand, it would be interesting to distinguish between what is meant by a skill and what is meant by the concept of competence. In fact, a competence is an ability encompassing cognitive skills, attitudes and other non-cognitive components, whereas a skill is often used to designate an ability to perform complex motor and/or cognitive acts with ease and precision as well as adaptability to changing conditions (Rychen \& Tiana, 2004). Therefore, competencies need adequate and efficient skills and attitudes to be accomplished. According to Rychen and Tiana (2004:21):"... each competence corresponds to a combination of interrelated cognitive and practical skills, knowledge, motivation, values and ethics, attitudes, emotions and other social and behavioural components that together can be mobilized for effective action in a particular context."

Furthermore, different aspects are, by way of consequence, developed by implementing these competencies and skills. These aspects are linked to the ability of the learner to be active in a more interactive environment, his capacity to develop and criticize pedagogical offers, ask pertinent questions about the main elements of a learning structure, as well as a determination to create new ways and find solutions to complex elements discovered in new contexts.

Accordingly, a demanding and very competitive world has pushed pedagogical thinkers to take into account new skills and qualities that learners should be equipped with to deal with the new challenges that are shaping a more globalized context (Kamehameha Schools, 2010). Former abilities needed in traditional professional contexts, which consisted in mastering basic trade conditions -based on basic intellectual abilities- as well as an adaptation to the local environment, are no longer the unique aspects that a worker should have. In fact, learning new skills come to confirm the necessity of constantly adapting to new situations, by creating and strengthening social links and develop inventive attitudes supposed to boost individuals' creative abilities. This can be possible by launching important initiatives to foster his autonomy and enrich his ability to prosper in a collective framework.

Besides, we live in a constantly changing world where technology and mainly its mastery has become an inescapable vital element in an overwhelming digital era. Thus, the use of technology can also be determinant in the learner's personal development and accompany him to be a successful element in any organization, where he should also display a wide range of aptitudes such as effective communication abilities, a rapid adaptation to new and complex situations and a disposition to invent new elements supposed to cope with local hindrances.

\section{Key Competencies and LMD students' needs}

It is essential to note, however, that lectures at university often tend to concentrate on gaining and accumulating knowledge, neglecting the development of other aspects such as communicating in different contexts and via different means or critically thinking and problem-solving. Moreover, the development of some skills and attitudes has very rarely constituted a priority for our teachers. At the same time, there is, today, a pressing need to equip LMD learners with adequate skills. On the one hand, to be part of and 
function in heterogeneous groups, and on the other hand, to act autonomously and reflectively so that they could express their needs and look for efficient ways to achieve their personal objectives. Reflectivity requires awareness, and at the same time, a control of the different elements and variables available in a given environment, as it is explained in a 2010 Kamehameha Schools report: "More than technological expertise, 21 st century skills refer to content knowledge, literacy and proficiencies that prepare individuals to meet the challenges and opportunities of today's world,". Thus, this new conception of education represents a form of adaptation to the rules, languages and codes specific to one particular field. This skill would require learners to develop the ability to perceive the importance of social partners, materially and psychologically. It also represents an advantage to acquire the capacity to belong to and be a part of different and complex social entities by showing a commitment to them and by respecting their characteristics without neglecting their own particularities.

Accordingly, this new pedagogical tendency tries to propose innovative teaching methods supposed to differently conceive knowledge acquisition, something which go hand in hand with the LMD reform in Algeria. In fact, when it comes to our LMD learners, they need to be equipped with the following examples of skills.

\subsection{Critical Thinking}

This would require nurturing students' critical thinking skills to develop a tendency towards asking questions and thinking logically, developing imagination and a rational conception of things. It is also vital to make students able to analyze situations logically and with objectivity and reason.

\subsection{Relating to others and communicating}

This involves designing tasks requiring students to be open to others' own visions, thoughts and conceptions, with open-mindedness, by establishing a link between their personal view and the others', by learning how to present information or ideas and persuade an audience. There is a strong and narrow relationship between learning and the necessity to develop a kind of social competence able to guarantee success in different learning and professional environments. Everyone can feel the determinant element of contributing to the community by providing important contribution supposed to assure progress. There is another ability, which can be linked to a kind of social integration, which consists in seizing cross cultural elements, which can help to master a more practical and fruitful collaboration with people from different origins.

\subsection{Using language, symbols and texts}

Creating an environment that allows a maximum exploitation and use of texts, language and symbols available to the learners through different literary genres that provide content and meaning and naturally enrich the learning situations.

\subsection{Managing Self}

Encouraging learners' personal capacity to determine learning objectives, and be responsible at the moment of selecting their pedagogical priorities. This would involve making learners able to reflect on their learning, by evaluating their attitudes towards learning a language, and towards the world that surrounds them.

\subsection{Participating, contributing and problem-solving}

It is the ability to take part in a cooperative process within one or several communities and be able to provide personal contributions and experiences to enrich the learning environment and solve problems through collaboration and team work. 


\subsection{Creativity and Innovation}

This competence Involves proposing alternatives by thinking to new possibilities of doing things and from new perspectives with new ideas or with conceiving again already established ones.

\subsection{Learning from doing}

It is an attempt to develop learners' abilities by practising in real-life contexts to easily adapt to the professional world. It is clear today that equipping learners with only technical skills is no more sufficient. Indeed, they need to be equipped with the skills that would allow them to be employed -but not only-and to participate to the socio-economic development of the country.

\section{Practical Implications}

It is to be noticed that both pedagogical conceptions of learning practices, i.e. the LMD system and the use of key competencies, share common features and philosophies of how students can reach optimal advantage from a learning context.

Consequently, by involving the students in the conception of their own pedagogical content, both systems can foster autonomy of the learners to adapt their own learning styles to the chosen objectives. This can be possible, for example, by the inclusion of the feedback technique that helps them to generate their views, feelings and perceptions of the teacher's pedagogical approach. In addition, sharing their learning experiences with their teacher is so crucial at the moment of conceiving any pedagogical offer.

Encouraging the interaction among learners is also something recommended by both The LMD system and the teaching of competencies and skills. The ability to create debates, to listen to each other and to share common learning experiences can help them to positively approach learning in an progressive environment.

Since the LMD teaching and learning priorities could be achieved through the implementation of Key Competencies, it would be recommended for the teacher to explicitly make use of them and explain to his students their importance whenever the learning situation reveals its occurrence. Furthermore, key competencies encourage the establishment of learning conversations that could reveal valuable details about the learners' styles and needs. All these initiatives are possible thanks to the new learning spirit that the LMD System is supposed to bring, in order to change the prevailing old instructional behaviours and reach an optimal learners' improvement.

A written expression session could, for example, integrate and allow the implementation of the different Key Competencies explained to the learners, who would feel free, for example, to give their opinions about the teaching process and the kind of activities that can suit them best. They can also be allowed to propose essay topics that make them better express their writing styles and abilities. In addition to this, an oral expression session, could for instance, foster learners' ability to react positively in conversations through communicating in a critical and constructive manner. Teachers can encourage them to speak freely and develop their confidence in personal opinion expression, and when speaking in public, as well as develop positive attitudes towards Intercultural communication along with the respect and understanding of cultural differences.

Moreover, explaining explicitly Key Competencies and their practical implications could incite learners to reveal their weaknesses in the perspective to be analysed and efficiently treated. Working inside a collective framework, which implies cooperation with other students, could also have a positive pedagogical impact and represent a source of mutual contributions.

Furthermore, the new pedagogical spirit which encourages the inclusion of innovative instructional elements, can also recommend the adoption of a new assessment approach. Indeed, formative assessment, which hints at discovering some aspects to be developed, and which principally seeks the improvement of learners, rather than simply evaluating their work, can be of a high pedagogical importance. The valuable feedback which results from it can be a useful source of information for the teacher to redirect his teaching approach. An interesting idea of how efficiently assess learners can be, for 
example, the Multiple Choice Question, accompanied with further questions supposed, thanks to answers provided by learners, to elicit important exploitable data.

Besides, capitalizing on past experiences can be very useful and can be possible thanks to the numerous possibilities provided by the electronic devices. It can be achieved by creating an electronic portfolio which would record the learners' different developmental stages. This can be a practical element that can help the teacher to further sharpen his teaching strategies.

One of my teaching and didactic priorities has become the implementation of Key Competencies and innovative skills. It did encourage me create learners'-centered initiatives, where the objective can be to incite them to make use of the maximum of this new category of skills. Indeed, it is possible to conceive activities, where learners can make use of the wide range of the competencies mentioned above. Asking them for example to make a research, written in English- which is a foreign language for them- about a significant decisive period in the history of their country, has revealed, among them, an encouraging ability to communicate with each other trying to take profit from a valuable collaboration where different students can bring their personal contributions, at different learning levels, whether linguistically, culturally, and even psychologically. These kinds of activities show that students can improve their performances when they are invited to critically think about a particular aspect, and can even make use on a frequent basis of his ability to create links between the different elements of a topic, displaying a great sense of innovation that can in many cases solve problems that can arise when practicing such pedagogical activities.

In addition, Multimedia means have become very important at the moment of trying to improve in a more interactive way the ability of the learner to develop communication abilities and to enrich his lexical competence. Using the net and modern technological devices can foster the ability of the learner to create a permanent learning channel that can help him to have access to different kinds of sources of information that contain a necessary content for setting and meeting objectives. The endless possibilities of Elearning provide, indeed, a vital source of self-development.

The LMD reform in Algeria comes to incite teachers to adopt new didactic attitudes that can differ from traditional ones where learners were not the center of interest. This new academic spirit has encouraged me when teaching Management and Business students to create other projects where they should actively exploit, in accordance with both the Official Reform and the spirit of helping to assimilate modern competencies, this new set skills. Indeed, they have been involved in a series of mini projects, more concretely: virtually creating start-ups. This initiative implied not only the use of their basic knowledge related to economy and business, but also the possibility of practicing it in a foreign language, such as English. Such experiences, supposed to recreate real life-inspired situations, encourage students to express their learning needs and take into account their particular profile. Their diversity can also be crucial in maintaining at high levels both their interest and motivation. These activities can also create situation where learners make use of a variety of qualities and aptitudes such as negotiating in a foreign language or using different electronic new media devices, lik as computers and tablets.

Moreover, and in order to better study learners' adaptation to these new pedagogical orientations, a study has been conducted where thirty (30) students were given a questionnaire. They were asked to choose, from a set of competencies, the ones that they feel can develop when practicing classroom activities. The results, as shown in table 1.1, indicate that, a majority of the respondents (from $56 \%$ to nearly $86 \%$ ) declared having developed the totality of competencies, when dealing with new kinds of assignments.

Table 1. Students' Choice of Modern Skills and Competencies

\begin{tabular}{|c|c|c|}
\hline MODERN SKILLS AND COMPETENCIES & NUMBER OF RESPONDENTS & PERCENTAGE (\%) \\
\hline Managing Self & 19 & 63.33 \\
\hline Creativity and Innovation & 17 & 56.66 \\
\hline Learning from doing & 21 & 70 \\
\hline Problem-solving & 18 & 60 \\
\hline
\end{tabular}




\begin{tabular}{|c|c|c|}
\hline Relating to others and communicating & 25 & 83.33 \\
\hline Experiencing Real-Life Situations & 26 & 86.66 \\
\hline Developing Autonomy & 21 & 70 \\
\hline
\end{tabular}

Questionnaires are useful tools for data eliciting. They can be used to better collect insightful clues that can contribute to optimally observe the teaching/learning situation. Indeed, when trying to analyze the different answers concerning learners' perception about these new kinds of activities, results reveal that their opinions can justify teachers' new pedagogical approaches which are directly linked to objectives put forward above.

Moreover, the same group of students was invited to express themselves about if the competencies mentioned above should be more developed through various motivating activities and mini-projects. Once again, and as Table1.2 indicates, a big majority feels the need to further develop them. They seem to have seized their pedagogical importance.

Table 2. Students' Willingness to Develop Modern Skills and Competencies

\begin{tabular}{|c|c|c|}
\hline & NUMBER OF RESPONDENTS & PERCENTAGE (\%) \\
\hline Yes & 24 & 80 \\
\hline No & 6 & 20 \\
\hline
\end{tabular}

Accordingly, students seem to appreciate innovative pedagogical initiatives, which can encourage them to perceive learning in a different way. They like to be engaged in new experiences which can foster their corresponding personal qualities. Thus, teachers should maintain this fruitful environment, if proposed purposefully. In fact, it can lead to significant positive results.

Furthermore, the new teaching spirit which tries to optimize the best teaching and learning conditions for students is a proof that Teachers' mission tends to have as an objective to discover the different areas linked to their students' daily needs. They are encouraged to initiate projects where learners have to speak about their own experiences, an essential feedback meant to improve the way teaching should be carried out.

\section{Conclusion}

The role of higher education in coping with globalization involves developing fundamental and transferrable competencies and among them' learning to learn' as well as making students acquire appropriate skills-that are up-dated all along their lives in the objective of making them become life-long learners in a constantly and rapidly changing world, contributing to their society's development. In this context of things, it s essential that teachers and decision-makers in the field of higher education find answers to the question: What do our learners need to learn and what skills and competencies they need to be equipped with in order to function appropriately and efficiently in their future workplace and, therefore, can respond successfully and with responsibility to the challenges of the 21 st century.

The new socio-economic development challenges, affecting our country today in the context of an increasingly interconnected world have, indeed, to be taken into account for their implications for our LMD teaching. Today, more than ever, the Algerian university is confronted to many challenges and has to urgently provide concrete actions in view of operating significant changes, allowing our students to have the necessary knowledge, skills and competencies they would need for the future.

Thinking of new considerations and approaches concerning the ways learners should acquire knowledge is apparently the priority of both the LMD system and the new didactic tendency which includes some key competencies in the learning process such as the learner's autonomy, involvement in the conception of pedagogical tools and the ability to take part in a collective learning approach. In fact, these 
objectives have always been a priority for the LMD system practitioners. Therefore, the LMD English curriculum specificities should adapt to change so that they fulfil the objective-among several others- of being at the service of the country's economy and society, but also of personal achievement and success in a constantly and rapidly changing global world we are inevitably and inescapably part of.

\section{References}

Acedo,C., \& Hughes, C. (2014). Principles for learning and competencies in the 21st century; in Prospects. Quarterly review of comparative education, n¹72 . December, IBE, Geneva, 503-525.

Crisan, A. (2006). Current and Future challenges in Curriculum Development: Policies, Practices and Networking for Change. IBE; Humanitas Educational; Bucharest.

Jonnaert, P., Masciotra, D., Barrette, J., Morel, D. \& Mane, Y. (2007). From competence in the curriculum to competence in action. Prospects (Quarterly review of comparative education), Vol. $142, \mathrm{n}^{\circ} 02$, June, International Bureau of Education,Geneva,185-204.

21 st Century Skills for Students and Teachers. Kamehameha schools, research \& evaluation d ivision, August, 2010.

Recommendations of the European Parliament and of the Council of Europe on Key Competencies for Life-Long Learning (2006). Europa website, Summaries of European Union Legislation (2011).

Roegiers, X (2007). Curricular reforms guide schools: but where to ?". Prospects (Quarterly review of comparative education), Vol. 142, n02, June, International Bureau of Education, Geneva,155-182.

Rychen, D.S \& Tiana, A (2004). Developing Key Competencies in Education: Some Lessons From International and National Experiences. Studies in Comparative Education, International Bureau of Education, Geneva.

Tiana, A. (2000). Contenues ou compétences? Une nouvelle approche. Revue Internationale d'éducation, $\mathrm{n}^{\circ} 25$, Hambourg, 19-22.

UNESCO Position Paper on Education post-2015 (2014). 